\title{
Utilization of Intron-flanking EST-specific Markers in the Phylogenetic Analysis and Parentage Identification of Rhododendron Species and Hybrids
}

\author{
Hui Wei \\ Department of Horticulture, Iowa State University, Ames, IA 50011 \\ Yan Fu \\ Department of Genetics and Developmental and Cellular Biology, Iowa State University, Ames, \\ IA 50011
}

\author{
Rajeev Arora ${ }^{1}$ \\ Department of Horticulture, Iowa State University, Ames, IA 50011
}

Additional INDEX wORDs. PCR, Ponticum, phylogeny, PJM, polymorphism

\begin{abstract}
Aвstract. Intron length polymorphisms were used to investigate relationships among eight Rhododendron L. species (R. catawbiense Michaux., $R$. minus Michaux., $R$. ponticum L., $R$. keiskei Miquel., R. arboreum Sm., $R$. dichroanthum Diels., ssp. scyphocalyx Cowan., $R$. maximum L. and $R$. dauricum L.) and two hybrid cultivars [i.e., $R$. 'PJM' (R. minus var. minus $\mathrm{X} R$. dauricum) and $R$. 'Chionoides' (R. ponticum $\mathrm{X}$ unknown)]. A total of 27 of these markers were used to estimate phylogenetic relationships among the species and draw inferences about the parentage of the cultivars, which is partially unknown. In general the expressed sequence tag-polymerase chain reaction (EST-PCR) marker-based phylogenetic map of the eight species is congruent with the currently accepted morphology-based classification of these species at the subgenus as well as the section level. However, the constructed phylogenetic tree revealed that, at the subsection level, two species, $R$. arboreum (subsection Arborea Sleum.) and $R$. dichroanthum (subsection Neriiflora Sleum.), are grouped under the same "clade" ( $80 \%$ bootstrap score), suggesting that these species are more closely related than indicated in the current classification system that places them in separate subsections/clades. Moreover, our phylogenetic analysis of the three species belonging to section Ponticum G. Don. demonstrated a closer phylogenetic relationship between $R$. ponticum and $R$. maximum (bootstrap score of $74 \%$ ) than between these species and $R$. catawbiense; such observation is consistent with a recent phylogenetic analysis of section Ponticum by Milne (2004) using the sequences of a chloroplast gene. Parentage analysis for the two cultivars confirmed the interspecific lineage of $R$. 'PJM' and provided genetic support for the speculated $R$. ponticum and $R$. maximum parentage of $R$. 'Chionoides'. Our results indicate that, in addition to their use in mapping studies, intron-flanking EST-based PCR markers are valuable tools for conducting phylogenetic and parentage analyses and/or gene flow studies.
\end{abstract}

Rhododendrons are among the most important woody landscape plants. Broadleaf, evergreen members of the genus Rhododendron (Ericaceae) are distributed throughout the Northern Hemisphere, ranging from tropical to polar climates (Leach, 1961). Species diversity has been used extensively by breeders to develop new cultivars or hybrids suitable for landscapes. Rhododendron breeders often strive to combine ornamental diversity found in less cold-hardy tropical taxa with the superior cold hardiness of northern hemisphere species to develop new ornamental cultivars for colder climates. Phylogenetic relatedness, or lack thereof, of species can provide breeders with useful insights into the breeding strategies. Therefore, development of molecular markers is important for the phylogenetic studies.

Phylogenetic and parentage analyses have received increasing interest recently for studying the evolutionary relationship among species and for the inference of family relationships and mating sys-

Received for publication 28 Mar. 2006. Accepted for publication 2 Aug. 2006. This research was supported, in part, by a grant from Landscape Plant Development Center, Mound, Minn. This journal paper of the Iowa Agriculture and Home Economics Experiment Station, Ames, Iowa (Project 3601) was supported by Hatch Act and State of Iowa funds. We are grateful to Dr. Stephen L. Krebs, David G. Leach Research Station of the Holden Arboretum (Mentor, Ohio), for his constructive suggestions toward the preparation of this manuscript.

'Corresponding author; e-mail: rarora@iastate.edu; phone: 1-515-294-0031; fax: 1-515-294-0730. tem for various plants, including horticultural species. Numerous genetic markers have been employed for clonal diversity studies, map construction and the quantitative trait loci (QTL) analysis or fingerprinting in rhododendron, including isozymes (Krebs, 1995), randomly amplified polymorphic DNA (RAPD) (Iqbal et al., 1995), and amplified fragment length polymorphism (AFLP) (De Riek et al., 1999; Dunemann et al., 1999; Escaravage et al., 1998; Pornon et al., 2000). Recently, EST-PCR-based markers have been developed for DNA fingerprinting and genetic relationship studies in blueberry (Vaccinium L. spp.), also an Ericaceous member like rhododendron (Rowland et al., 2003).

Our group recently released rhododendron ESTs generated from the cDNA libraries that were prepared from nonhardened (summer-collected) and cold-hardened (winter-collected) leaf tissues (Wei et al., 2005a). We then used gene sequence alignment between rhododendron ESTs and the genomic sequences of arabidopsis [Arabidopsis thaliana (L.) Heynh.] homologs to design "intron-flanking" EST-PCR based primers that would anneal to the target DNA in conserved exon regions and amplify across the more highly diverged introns (Wei et al., 2005b); a similar primer design method was previously used by Choi et al. (2004) who aligned Medicago truncatula Gaertn. ESTs with the genomic sequences of arabidopsis homologs and designed intron-targeting primers for developing EST-based markers to construct a genetic map of M. truncatula. Consistent with the expectation that EST- 
PCR primers flanking less conserved intron(s) would generate relatively greater number of codominant polymorphic markers compared to the traditional approach (Pickering et al., 2004), the primers that we designed had significantly higher efficiency (61\% vs. 13\%, 4.7-fold) of polymorphism-detection compared with conventional EST-PCR methods (Wei et al., 2005b). Thus, EST-PCR based markers can serve as an efficient and relatively inexpensive molecular approach in phylogenetic or mapping studies; EST-based markers are particularly more meaningful for QTL-mapping because they target expressed genes.

The objectives of the current study were 2-fold: The first objective was to use the polymorphism data generated by intron-flanking primers to conduct phylogenetic analysis of eight Rhododendron species and compare it against currently accepted morphology-based classification of these species to test the usefulness of these markers in establishing evolutionary relationships. Two recent reports used the sequence data of chloroplast genes [mat $\mathrm{K}$ and $\operatorname{trn} \mathrm{L}-\mathrm{F}$ (Milne, 2004)] and a nuclear gene [RPB2-1 (Goetsch et al., 2005)] to conduct phylogenetic analysis across Rhododendron genus; both studies used the sequence data of one or two genes and the former constructed phylogeny based on plastids. Milne (2004) noted that the plastid-based phylogeny does not necessarily match the evolutionary tree for the species because plastids' history may differ from the species containing them. Moreover, since the evolutionary rates vary among different nuclear genes (Small et al., 2004) and therefore use of one or two genes might not provide a well resolved phylogenetic analysis, the current study used the polymorphism data for a batch of 27 nuclear genes' EST-PCR markers.

The second objective was to determine if the EST-PCR-based marker system could be a useful tool in establishing/substantiating the parentage information for an interspecific rhododendron hybrid cultivar. Specifically, we tested if $R$. maximum, the long suspected but never confirmed as a parent of the rhododendron hybrid $R$. 'Chionoides' (Salley and Greer, 1986), was indeed one of the parents of this cultivar; it is well established that $R$. ponticum is the seed parent of this hybrid whereas, based on certain morphological similarities, $R$. maximum is believed to be the pollen donor in this cross but this notion lacks any molecular support. We used EST-PCR primers in the genomic PCR analysis for two rhododendron cultivars ( $R$. 'PJM', a positive control with established parentage and $R$. 'Chionoides') and compared their polymorphism patterns with their known or probable parents.

\section{Materials and Methods}

Plant materials. Eight Rhododendron species and two hybrid cultivars were used in this study. The species were selected from two subgenera of Rhododendron - subgenus Hymenanthes (Blume) Endl., the non-scaly leaved or elepidote species (numbers $1,3,5,6$, and 8), and subgenus Rhododendron L., the scaly leaved or lepidote species (numbers 2, 4, and 7) (Table 1). The two hybrid cultivars used were $R$. 'PJM' and $R$. 'Chionoides'.

Genomic DNA extraction. Genomic DNA was extracted, using the protocol described by Wei et al. (2005b), from the young leaves collected in spring (May 2004) at the Horticulture Experimental Station (Ames, Iowa) of Iowa State Univ. DNA was quantified by gel electrophoresis analysis by comparing with DNA concentration standards.

"Intron-Flanking” EST-Primers. The EST-specific primer pairs were designed as described in our previous study (Wei et al., 2005b), which demonstrated that "intron-flanking” EST-primers generate relatively higher PCR band polymorphism than conventionally designed EST-primers. Twenty-seven primer pairs were previously demonstrated to generate polymorphic PCR bands in the surveyed six Rhododendron species (Wei et al., 2005b); the current study extended the application of these primers to eight species and two hybrids for phylogenetic and parentage analyses. The sequences for these primers were previously described in the supplemental Table 1 of Wei et al. (2005b).

Touchdown PCR and Sequencing of Genomic PCR PRODUCTS. Genomic DNA was amplified by touchdown PCR (Don et al., 1991) modified as follows: PCR mixtures were incubated for 2 min at $92{ }^{\circ} \mathrm{C}$ for initial denaturation, followed by the first 10 cycles of denaturation at $94^{\circ} \mathrm{C}$ for $30 \mathrm{~s}$, annealing for $30 \mathrm{~s}$ at selected temperatures (see below) and elongation at $72{ }^{\circ} \mathrm{C}$ for $1 \mathrm{~min} 30 \mathrm{~s}$; the annealing temperature was decreased by $0.9^{\circ} \mathrm{C}$ per cycle during the first 10 cycles from 69 to $60^{\circ} \mathrm{C}$ to increase the specificity of the amplification. After the first 10 cycles as described above, 25 additional cycles were carried out at $94{ }^{\circ} \mathrm{C}$ for $30 \mathrm{~s}, 60{ }^{\circ} \mathrm{C}$ for $30 \mathrm{~s}$, and $72^{\circ} \mathrm{C}$ for $1 \mathrm{~min} 30 \mathrm{~s}$ followed by a final 10 -min extension at $72^{\circ} \mathrm{C}$. PCR amplification was carried out in a $20-\mu \mathrm{L}$ reaction containing $20 \mathrm{ng}$ of DNA, $0.2 \mathrm{~mm}$ of dNTP mix, $20 \mathrm{~mm}$ of $\mathrm{MgCl} 2,600 \mathrm{~nm}$ of each of the forward and reverse primers, 1 unit of Taq DNA polymerase and $2 \mu \mathrm{L}$ of the supplied 10-fold concentrated PCR buffer (Invitrogen Life Technologies, Carlsbad, Calif.). PCR products were separated by agarose gel electrophoresis; band sizes were determined against $1 \mathrm{~kb}$ plus DNA ladder or $100 \mathrm{bp}$ DNA ladder (Invitrogen Life Technologies, Carlsbad, Calif.). To test the PCR specificity, a total of 12 PCR bands were gel-purified and sequenced as previously described (Wei et al., 2005b).

Evaluation of PCR band POLYMorphism. After the separation by $1.2 \%(\mathrm{w} / \mathrm{v})$ agarose gel electrophoresis, the genomic PCR band patterns were scored based on the size and presence/absence polymorphisms. They are coded as "character states" (i.e., the alternative forms of a homologous feature in different species) for the phylogenetic analysis of eight Rhododendron species. The symbols used for band scoring were: "S" for single band (S1, single type 1; S2, single type 2), "D" for double bands (D1, double type 1; D2, double type 2), and "T" for three bands (T1, triple type 1; T2, triple type 2).

Phylogenetic tree CONSTRUCtion fOr RHododendron SPECIES. Following band scoring, the coded genomic PCR band pattern data were input into PAUP* (Swofford, 2002) to perform phylogenetic analysis. The bootstrap trees using both parsimony and distance models were used for the tree construction.

Parentage analysis of Rhododendron cultivars. The cultivars $R$. 'Chionoides' and $R$. 'PJM' were used to test the ability of the intron-flanking EST markers to confirm known lineages or elucidate unknown parentages. Two related approaches were used here. The first was "additive," using the codominant EST-specific markers to look for unique parent (species) markers that are both present in the hybrid. The other approach was "subtractive," ruling out possible parents based on their PCR banding patterns relative to the hybrid. According to this principle, basically the presence of alleles at any given locus in a hybrid offspring would rule out all those species as potential parents which could not have contributed these alleles; for the EST-based gene-specific markers, such as used in this study, it is reasonable to assume that the PCR product bands correspond to specific alleles. 
Table 1. The eight Rhododendron species and two hybrid cultivars used for the phylogenetic and parentage analyses.

\begin{tabular}{|c|c|}
\hline Rhododendron genotypes & Native range \\
\hline \multicolumn{2}{|l|}{ Species for phylogenetic analysis } \\
\hline 1. $R$. catawbiense ('Catalgla' $\mathbf{H})^{\mathrm{z}}$ & Mid-Atlantic U.S. (North Carolina and Virginia) \\
\hline 2. R. minus $^{\mathrm{y}}\left(\mathrm{L} 62-570^{\mathrm{H}}\right)$ & Southeastern U.S. (Florida, Tennessee, Georgia, North Carolina, Alabama) \\
\hline 3. R. ponticum $(76 / 411$ "B"R $)$ & Southwestern Eurasia \\
\hline 4. R. keiskei (L59-63A $\left.\mathrm{A}^{\mathbf{H}}\right)$ & Japan \\
\hline 5. R. arboreum $\left(64 / 118^{\mathrm{R}}\right)$ & Southern Asia \\
\hline 6. $R$. dichroanthum ssp. scyphocalyx (nо. $\left.{ }^{\mathrm{H}}\right)$ & Southern China \\
\hline 7. R. dauricum $\left(67-143^{\mathrm{H}}\right)$ & Eastern Siberia, northern China, Japan \\
\hline 8. R. maximum $\left(65-285^{\mathrm{H}}\right)$ & Eastern North America (Nova Scotia to Georgia) \\
\hline \multicolumn{2}{|l|}{ Cultivars for parentage analysis } \\
\hline \multicolumn{2}{|l|}{ 'PJM' } \\
\hline \multicolumn{2}{|l|}{ (R. minus var. minus $\times$ R. dauricum) } \\
\hline \multicolumn{2}{|l|}{ 'Chionoides’ } \\
\hline \multicolumn{2}{|l|}{$(\text { R. ponticum } \times \text { unknown })^{\mathbf{x}}$} \\
\hline
\end{tabular}

\section{Results and Discussion}

PCR BAND POLYMORPHISM AND PATTERNS ACROSS SPECIES. With a goal of constructing an evolutionary relationship of selected Rhododendron species, 27 EST-PCR primers (all those that produced PCR band polymorphisms using six Rhododendron species in our previous study; Wei et al., 2005b) and the genomic DNA from eight Rhododendron species as templates were used for genomic PCR amplification and subsequent detection of PCR band pattern polymorphism; as examples, the PCR banding patterns generated by six of these 27 EST-PCR primer pairs across the genomic templates of eight Rhododendron species are illustrated in Fig. 1. The specificity of genomic PCR amplification was verified, as previously described (Wei et al., 2005b), by gelpurification and sequencing of the PCR products for 12 markers (seven in previous study, Wei et al., 2005b; five in current study) (data not shown).

A given EST-specific marker was considered polymorphic, for which at least one Rhododendron species' PCR banding pattern was different from the other seven. The PCR product band patterns were coded based on the number of bands in each of the PCR amplification as described in Materials and Methods. For illustration, two such cases (Primers C35 and C42) are given in Fig. 1, in which the PCR bands are scored in the form of character state as "S" (single-band), "D" (double-band), or "T" (triple-band) in a combination with a number to distinguish band patterns within the same type. A definitive explanation for the generation of double or triple bands (as opposed to only single bands as expected for the codominant markers) for some of the primers used in this study is not clear. However, these multiple bands may, potentially, represent splice variants. Alternatively, these primer pairs may span a region of introns with high variability. Multiple bands may also be caused by the rearrangements of specific genes during evolution process. Future studies involving sequencing of individual bands and isolation of their full-length genes would provide insight into some of these questions.

Phylogenetic analysis aCross eight Rhododendronspecies. The polymorphism data of coded, differential genomic PCR band patterns for all 27 primer pairs (data not shown) were used to construct a phylogenetic tree. The two bootstrap trees constructed using parsimony and distance model, respectively, had identical topology. The phylogenetic tree using distance model is presented and compared with the currently accepted classification system for Rhododendron species in Fig. 2.

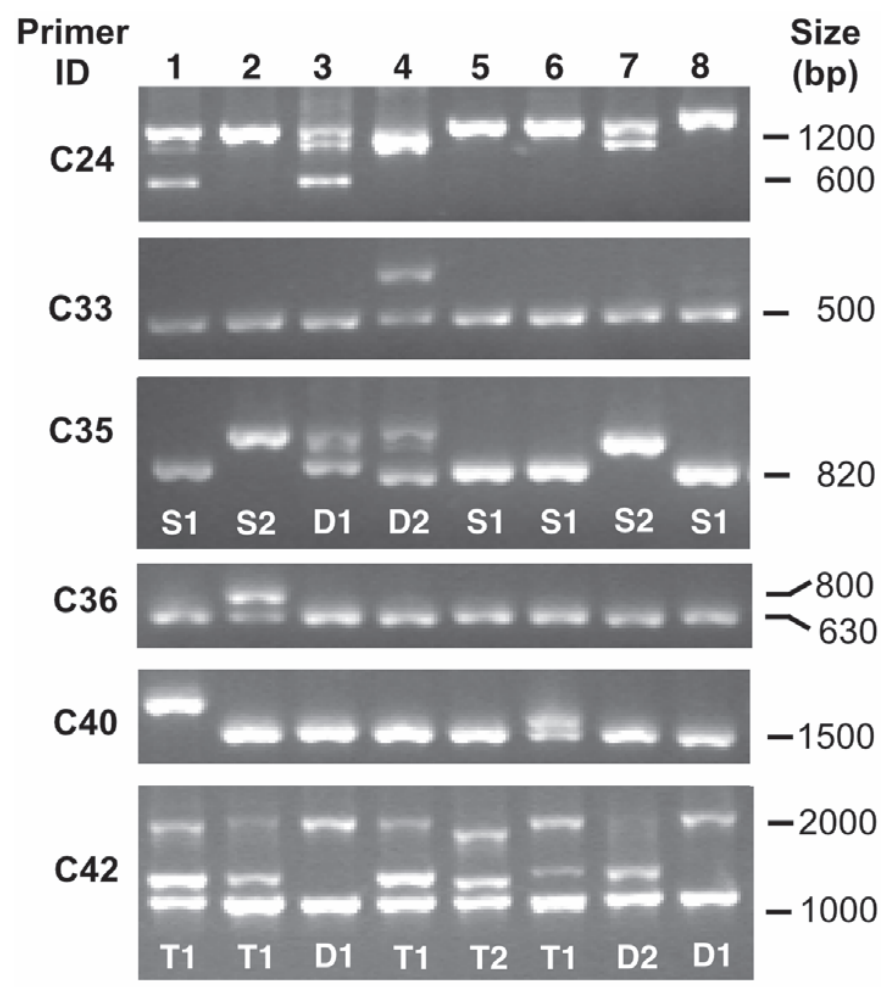

Fig. 1. Polymorphism patterns of PCR product bands using EST-specific primers in amplifying genomic DNA from eight Rhododendron genotypes. Only six out of 27 EST-PCR based markers are shown here with their PCR product band patterns. The order for the genotypes in lanes 1-8 is: 1) $R$. catawbiense 'Catalgla', 2) $R$. minus, 3) $R$. ponticum, 4) $R$. keiskei, 5) $R$. arboreum, 6) $R$. dichroanthum, 7) $R$. dauricum, and 8) R. maximum. The full list of PCR band patterns for all the primers are not shown. The explanation for symbols used in the figure can also be found in the text; basically, for each individual gel image, S1 and S2 represent different "single-band type," D1 and D2 represent different "double-band type," and T1 and T2 represent different "triple-band type"; ID = identification, bp = base pairs. 


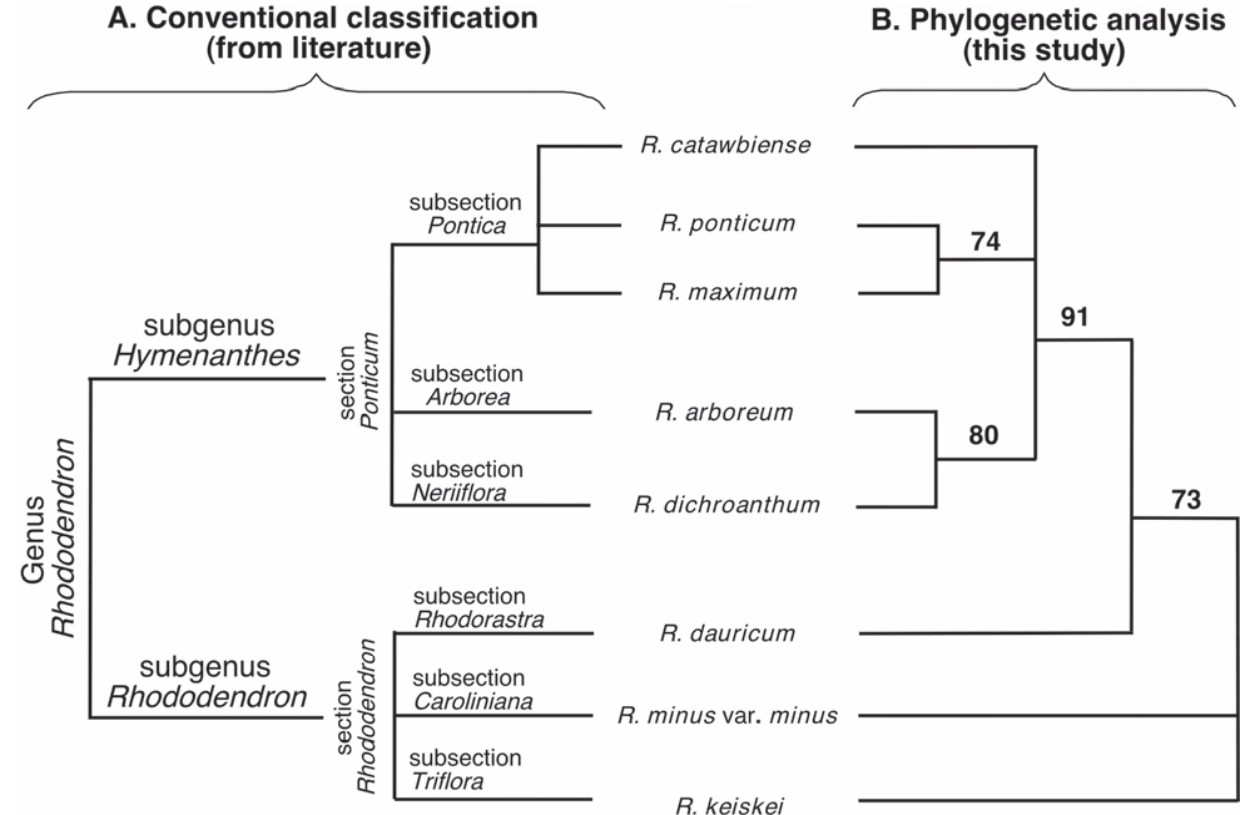

Fig. 2. The classification and phylogenetic analysis of the surveyed eight Rhododendron species. (A) The conventional classification (Chamberlain et al., 1996; Cox and Cox, 1997); (B) The phylogenetic bootstrap tree of the surveyed Rhododendron species using the PCR band pattern data generated from the primers based on the 27 transcript sequences. Numbers at the branch nodes indicate the percentages of bootstrap values (based on 1000 bootstraps).

According to current and generally accepted morphologybased classification system (Chamberlain et al., 1996; Cox and Cox, 1997), the genus Rhododendron can be divided into eight subgenera. Plants generally recognized as "true" rhododendrons belong to two of the subgenera: Hymenanthes and Rhododendron. The eight species surveyed in current study belong to these two subgenera, and their currently accepted classification is illustrated in Fig. 2A.

Our data (Fig. 2B) indicated that the phylogenetic tree for eight Rhododendron species using EST-PCR banding patterns is congruent at the subgenus level with the current classification system (Fig. 2A): five species under subgenus Hymenanthes according to the current classification system ( $R$. catawbiense, $R$. ponticum, $R$. maximum, $R$. arboreum, and $R$. dichroanthum) are clustered together with a $91 \%$ bootstrap score, and the two classification approaches are also in agreement for $R$. dauricum, $R$. minus, and R. keiskei that belong to subgenus Rhododendron (compare Fig. 2A and 2B).

More interestingly, the phylogenetic tree revealed that $R$. arboreum (subsection Arborea) and $R$. dichroanthum (subsection Neriiflora) within the section Poticum, are grouped under the same "clade" ( $80 \%$ bootstrap score), suggesting that these two species are more closely related than what is apparent from the current classification system; a close relationship between these two species is consistent with their similar native distribution range (i.e., southern Asia and southern China) and near-similar cold hardiness (both species are generally considered as semihardy to tender).

Our results further revealed that of the three species within section Ponticum included in this study, $R$. ponticum and $R$. maximum were grouped under the same clade with a bootstrap score of $74 \%$ (Fig. 2B), whereas $R$. catawbiense fell under a different clade. The demonstrated closer phylogenetic relationship between $R$. ponticum and $R$. maximum than between these two and $R$. catawbiense is consistent with recent observations by Milne (2004) and Goetsch et al. (2005) based on their molecular systematics studies involving chloroplast genes (matK and $\operatorname{trn} \mathrm{L}-\mathrm{F})$ or a nuclear gene (RPB2), respectively, which highlights the feasibility and reliability of using EST-specific markers in phylogenetic analysis as conducted in the current study.

Rhododendron maximum is native to eastern North America, stretching from Nova Scotia (Canada) in the north to Georgia (United States) in the south; R. catawbiense is distributed in a rather "narrow" belt of mid-Atlantic region (North Carolina and Virginia) (Chamberlain et al., 1996; Cox and Cox, 1997); while $R$. ponticum is distributed throughout southwestern Eurasia including area south of the Black Sea (northern Turkey, Caucasus, and southeastern Bulgaria; native range) to Georgia, Armenia, Spain, Portugal and British Isles (Milne and Abbott, 2000). Milne (2004) suggested that within subsection Pontica, the diversification of $R$. maximum and $R$. ponticum may have happened $\approx 5-3$ million years ago and implied some form of trans-Atlantic migration through a brief land connection across northern Atlantic Ocean, or through the Bering Land Bridge (5.5-4.8 million years ago).

Significance OF EST-PCR MARKERS FOR PHYLOGENETIC ANALYSIS. Previous studies have used chloroplast DNA sequences

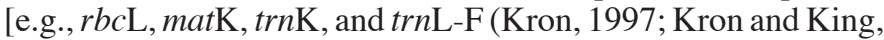
1996; Kurashige et al., 2001; Milne, 2004)] and nuclear ribosomal DNA sequences [nr18s (Gao et al., 2002; Kron, 1996)] to conduct phylogenetic analysis of Rhododendroideae (a subfamily within Ericaceae) and the genus Rhododendron. The current study used EST-PCR markers, which are based on nuclear gene sequences, to conduct the phylogenetic analysis of eight Rhododendron species. Recently, Goetsch et al. (2005) utilized nuclear gene RPB2-1's genomic sequences (which contain both introns and exons) to analyze the phylogenetic relationship among Rhododendron species. The use of nuclear genetic markers can increase the resolution and efficiency of phylogenetic analysis through potentially capturing more evolutionary events since the nuclear genome evolves at a faster rate than chloroplast or mitochondrial genome (Small et al., 2004). Furthermore, the use of intron-based genetic markers (Wei et al., 2005b and this study) is particularly advantageous because introns lack functional restraints and therefore evolve fast, which potentially enhances the resolution of closely-related taxa in phylogenetic analysis. Our results and that of Goetsch et al. (2005) demonstrate that the phylogenetic results for some species, based on the molecular data of nuclear genes, can deviate from the generally accepted classification systems of rhododendron, which are mainly based on morphological characters (Chamberlain et al., 1996; Cox and Cox, 1997). As demonstrated by Milne (2004) and Goetsch et al. (2005), a systematic re-analysis of the rhododendron classification using DNA sequence data can indeed generate a refined phylogenetic tree. To that end, the current study provides a cost-efficient, alternative approach of 
using EST-specific markers that allows the use of sequences from many nuclear genes.

Parentage analysis of hybrid $\boldsymbol{R}$. 'PJM' And $\boldsymbol{R}$. 'Chionoides'. Eighteen primer pairs (out of 24 tested) generated differential PCR product band patterns between or within the two hybrid groups studied (each group comprising the hybrid and it parents). Nine of these are illustrated in Fig. 3. The polymorphism patterns were used to explore the family relationship of two interspecific hybrids ('PJM', 'Chionoides') with their respective known and/or probable parents.

The first, scenario is where the hybrid PJM's PCR product band pattern is same as that of both of its both parents (i.e., $R$. minus var. minus Rehder. and $R$. dauricum); this is evident in banding patterns for Primers 23, 26, 34, 35, and 42 in which the hybrid PJM bands are indicated by the triangle symbol ( $\nabla$ ) (lane 2; Fig. 3 ). The second scenario is where one of the parents has one band while the other has two and one or both of these bands can be tracked in the hybrid. This pattern is generated by Primers C24, C25, and C36 for PJM hybrid and indicated by solid arrow ( $\uparrow$ ) (lane 1; Fig. 3). The third scenario is that the hybrid PJM hybrid has two bands, each of them likely to be inherited from one of the known parents. This case is exemplified by Primer 20, and indicated by * for 'PJM' (lane 2, Fig. 3).

In all the scenarios, the inheritance of PCR bands between the parents and the hybrid can be established (i.e., there is at least one common PCR band between each of the two parents and the hybrid R. 'PJM', thus allowing the parentage analysis and tracking of gene flow in this cross). Such an approach can be extended to the parentage analysis (i.e., confirming or excluding the probable parents) in hybrid $R$. 'Chionoides'.

Similar flow of genes (based on the tracking of PCR product bands) was also observed between the hybrid $R$. 'Chionoides' and its parents for all the primer pairs (18/24) that generated PCR band polymorphism (lanes 4-6, Fig. 3; results for only nine primers pairs are shown), which supports that $R$. maximum is likely a "true" parent for hybrid $R$. 'Chionoides', based on the screened EST-specific markers. Furthermore, by applying the "subtractive approach" (described in Methods section) to PCR product band patterns across eight Rhododendron species listed in Table 1 , one can exclude all species except $R$. maximum as being the potential parent of hybrid $R$. 'Chionoides', based on the "intrackability" of bands between the individual species and the hybrid; no common PCR band(s) are shared between the other seven species and the hybrid $R$. 'Chionoides' in at least five to nine (out of 27) primers' amplification products (data not shown). Taken all together, our data supports the long-suspected notion that $R$. maximum is likely the pollen parent for hybrid $R$. 'Chionoides' (Salley and Greer, 1986).

\section{Conclusion}

This study demonstrates the suitability of EST-PCR based markers for the phylogenetic and parentage analysis of Rhododendron species and cultivars. Although the genotype sample size used in our study was relatively small and represented only available samples at the initial stage of current project, the congruence of our results with that of a recent report by Milne (2004) about the cladistic assignment of $R$. ponticum and $R$. maximum (Fig. 2) supports the validity and the feasibility of using EST-specific markers in phylogenetic analysis. The cross-subsection "clade" of $R$. arboreum (subsection Arborea) and $R$. dichroanthum (subsection Neriiflora) demonstrated in this study (with a high bootstrap

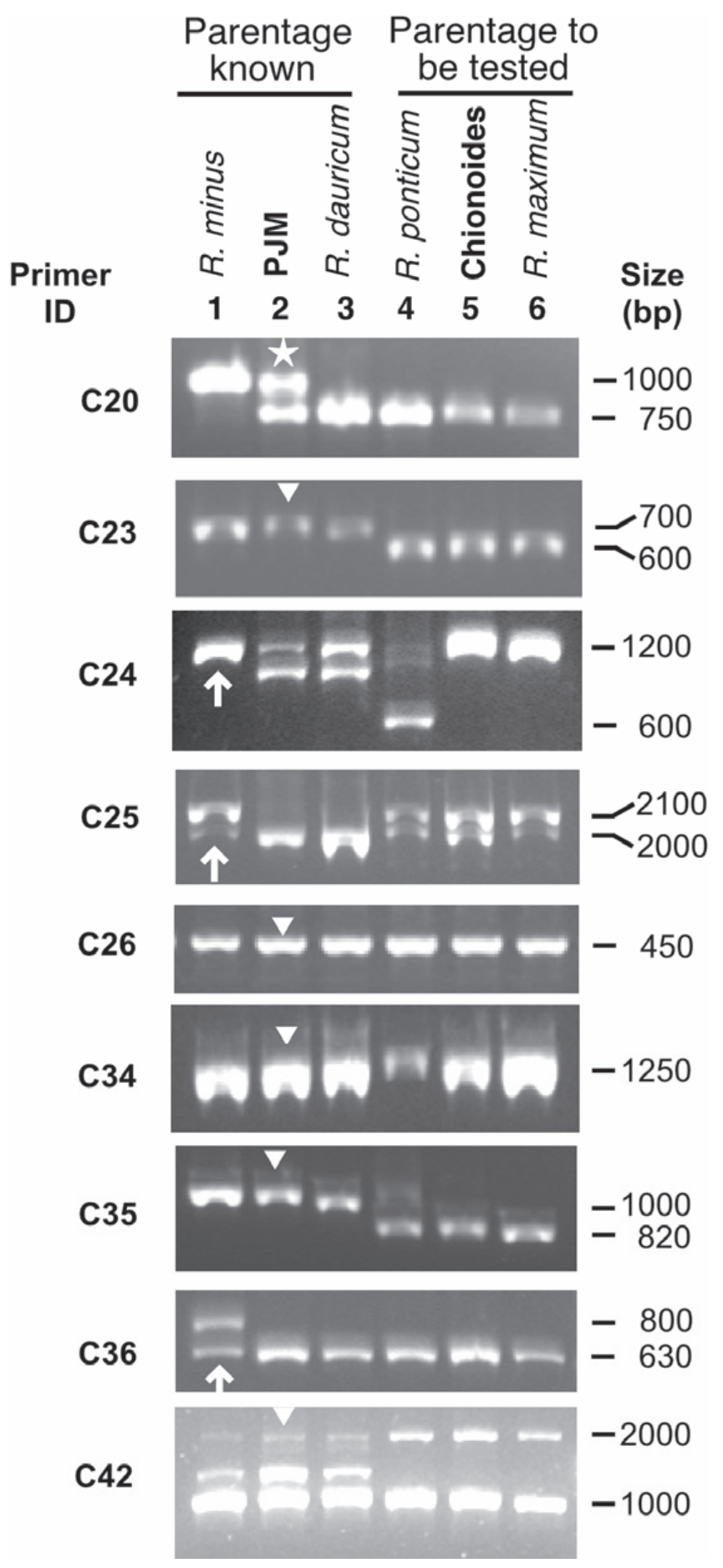

Fig. 3. Examples of polymorphism patterns for the parentage analysis of Rhododendron cultivars $R$. 'PJM' ( $R$. minus var. minus $\times$ R. dauricum) and $R$. 'Chionoides' $(R$. ponticum $\mathrm{x}$ unknown with $R$. maximum as the probable pollen donor parent) using EST-PCR based markers; ID = identification; bp $=$ base pairs.

score of $80 \%$ ) also provides a good lead for future studies using the greater number of genotypes to better understand the phylogenetic relationships within section Ponticum. Furthermore, considering the high efficiency and relatively low cost of EST-PCR based maker system, and their links to specific loci (genes), the utilization of such markers in rhododendron is anticipated to be applicable also to other species given the increasing availability of ESTs in public databases throughout woody taxa. 


\section{Literature Cited}

Chamberlain, D.F., R. Hyam, G. Argent, G. Fairweather, and K.S. Walter. 1996. The genus Rhododendron: Its classification and synonymy. Royal Botanic Garden, Edinburgh, Scotland.

Choi, H.K., D. Kim, T. Uhm, E. Limpens, H. Lim, J-H. Mun, P. Kalo, R.V. Penmetsa, A. Seres, O. Kulikova, B.A. Roe, T. Bisseling, G.B. Kiss, and D.R. Cook. 2004. A sequence-based genetic map of Medicago truncatula and comparison of marker colinearity with $M$. sativa. Genetics 166:1463-1502.

Cox, P.A. and K.N.E. Cox. 1997. The encyclopedia of Rhododendron species. Glendoick Publishing, Perth, U.K.

De Riek, J., J. Dendauw, M. Mertens, M. De Loose, J. Heursel, and E. Van Bockstaele. 1999. Validation of criteria for the selection of AFLP markers to assess the genetic variation of a breeders' collection of evergreen azaleas. Theor. Appl. Genet. 99:1155-1165.

Don, R.H., P.T. Cox, B.J. Wainwright, K. Baker, and J.S. Mattick. 1991. Touchdown PCR to circumvent spurious priming during gene amplification. Nucleic Acids Res. 19:4008.

Dunemann, F., R. Kahnau, and I. Stange. 1999. Analysis of complex leaf and flower characters in Rhododendron using a molecular linkage map. Theor. Appl. Genet. 98:1146-1155.

Escaravage, N., S. Queestiau, A. Pornon, B. Doche, and P. Taberlet. 1998. Clonal diversity in a Rhododendron ferrugineum L. (Ericaceae) population from AFLP markers. Mol. Ecol. 7:975-982.

Gao, L.M., D.Z. Li, C.Q. Zhang, and J.B. Yang. 2002. Infrageneric and sectional relationships in the genus Rhododendron (Ericaceae) inferred from ITS sequence data. Acta Botanica Sinica 44:1351-1356.

Goetsch, L.,A.J. Eckert, and B.D. Hall. 2005. The molecular systematics of Rhododendron (Ericaceae): A phylogeny based upon RPB2 gene sequences. Systematic Bot. 30(3):616-626.

Iqbal, M.J., D.W. Paden, and A.L. Rayburn. 1995. Clonal stability of RAPD markers in three Rhododendron species. J. Environ. Hort. 13:43-46.

Krebs, S.L. 1995. Enzyme fingerprinting of Rhododendron cultivars. J. Amer. Rhododendron Soc. 49: 210-215.

Kron, K.A. 1996. Phylogenetic relationships of Empetraceae, Epacridaceae, Ericaceae, Monotropaceae, and Pyrolaceae: Evidence from nuclear ribosomal 18s sequence data. Ann. Bot. 77:293-303.

Kron, K.A. 1997. Phylogenetic relationship of Rhododendron (Ericaceae). Amer. J. Bot. 84:973-980
Kron, K.A. and J.M. King. 1996. Cladistic relationships of Kalmia, Leiophyllum, and Loiseleuria (Phyllodoceae, Ericaceae) based on nucleotide sequences from $r b c \mathrm{~L}$ and nuclear ribosomal transcribed spacer regions (ITS). Systematic Bot. 21:17-29.

Kurashige, Y., J.I. Etoh, T. Handa, K. Takayanagi, and T. Yukawa. 2001. Sectional relationships in the genus Rhododendron (Ericaceae): Evidence from matK and trnK intron sequences. Plant Systematics Evol. 228:1-14.

Leach, D.G. 1961. Rhododendrons of the world and how to grow them. Scribner, New York.

Milne, R.I. 2004. Phylogeny and biogeography of Rhododendron subsection Pontica, a group with a tertiary relict distribution. Mol. Phylogenetics Evol. 33:389-401.

Milne, R.I. and R.J. Abbott. 2000. Origin and evolution of invasive naturalized material of Rhododendron ponticum L. in the British Isles. Mol. Ecol. 9:541-556.

Pickering, R., P.A. Johnston, and B. Ruge 2004. Importance of the secondary gene pool in barley genetics and breeding I. Cytogenetics and molecular analysis. Czech J. Genet. Plant Breeding 40:73-78.

Pornon, A., N. Escaravage, P. Thomas, and P. Taberlet. 2000. Dynamic of genotypic structure in clonal Rhododendron ferrugineum (Ericaceae) population. Mol. Ecol. 9:1099-1111.

Rowland, L.J., S. Mehra, A.L. Dhanaraj, E.L. Ogden, J.P. Slovin, and M.K. Ehlenfeldt. 2003. Development of EST-PCR markers for DNA fingerprinting and genetic relationship studies in blueberry (Vaccinium, section Cyanococcus). J. Amer Soc. Hort. Sci. 128:682-690.

Salley, H.E. and H. Greer. 1986. Rhododendron hybrids. A guide to their origins. Timber Press, Portland, Ore.

Small, R.L., R.C. Cronn, and J.F. Wendel. 2004. L.A.S. Johnson review No. 2. Use of nuclear genes for phylogeny reconstruction in plants. Austral. J. Systematic Bot. 17:145-170.

Swofford, D.L. 2002. PAUP*: Phylogenetic analysis using parsimony (*and other methods). Version 4. Sinauer Associates, Sunderland, Mass.

Wei, H., A.L. Dhanaraj, L.J. Rowland, Y. Fu, S.L. Krebs, and R. Arora. 2005a. Comparative analysis of expressed sequence tags from cold acclimated and non-acclimated leaves of Rhododendron catawbiense Michx. Planta 221(3):406-416.

Wei, H., Y. Fu, and R. Arora. 2005b. Intron-flanking EST-PCR markers: From genetic marker development to gene structure analysis in Rhododendron. Theor. Appl. Genet. 111:1347-1356. 